\title{
Application of mathematical logic for immunophenotyping of B-Cell precursor acute lymphoblastic leukemia (BCP-ALL)
}

\section{Gerhard Zugmaier ${ }^{*}$ and Franco Locatelli ${ }^{2}$}

${ }^{1}$ Department of Haematology, Oncology and Immunology, Pilipps University Marburg, Marburg, Germany

${ }^{2}$ Full Professor of Pediatrics, Sapienza, University of Rome, Director Department of Pediatric Hematology and Oncology IRCCS Ospedale Pediatrico Bambino Gesù, Rome, Italy

\section{Introduction}

The end of the 20th and the beginning of the 21st century has been an era of breakthroughs in medicine like the development of physics and chemistry from the 2 nd half of the 19th to the beginning thirties of the 20th century.

The foundation for this revolution in clinical science has been laid by the discoveries in translational science, having led to new treatment principles especially in hematology and oncology. But also, discoveries in all other areas have contributed to this development resulting in a scientific medicine also called evidence-based medicine [1].

Whereas theoretical physics, theoretical chemistry and theoretical biology are well-established disciplines, theoretical medicine has not yet been fully established.

Medicine has applied many different scientific disciplines for the benefit of patients. The role of logic in Medicine has been described especially for the diagnostic process [2-5]. It has been stressed that there is no diagnosis without logic and that logic provides the best textbook for medicine $[4,6]$.

We will demonstrate through the example of the B-cell precursor acute lymphoblastic leukemia (BCP-ALL) that mathematical logic, especially propositional logic, is suitable to make the definitions of diseases more precise and may help establish a theoretical medicine

\section{Mathematical Logic}

Mathematical Logic as known nowadays was developed among others by the mathematicians Gottlob Frege [7] and Guiseppe Peano [8], and the philosophers Bertrand Russell [9] and Ludwig Wittgenstein [10]. Especially the latter one and the mathematician Emil Post [11] simultaneously and independently developed the truth tables, which we also use in this study. Lukasiewicz [12] developed a 3-valued logic with the term "possible" in form of a propensity score. However, we apply the principle of the excluded middle, meaning that a proposition can only be either true or false, but not be something in between. For true propositions, we use the number 1, while for false propositions we use the number 0 . Based on outlined above, a proposition can only have one value at a time, 1 for "true" and 0 for "false". The values of 2 propositions can have 4 permutations.

\begin{tabular}{|l|l|}
\hline $\mathbf{A}$ & $\mathbf{B}$ \\
\hline $\mathbf{1}$ & $\mathbf{1}$ \\
\hline $\mathbf{1}$ & $\mathbf{0}$ \\
\hline $\mathbf{0}$ & $\mathbf{1}$ \\
\hline
\end{tabular}

There are $2 \mathrm{e} 4=16$ permutations possible for truth values of a composite proposition $\mathrm{AB}$ consisting of 2 single propositions, a proposition A", and a proposition $B$. This way the truth values of all propositions can be coded by a sequence of the numbers 1 and 0 . From the 16 possible logical connectives of 2 propositions, only 7 play a major role in logic in addition to the negation " $\left.\operatorname{not}^{\text {" }}(\rceil\right)$ :

$\wedge$ and (conjunction)

$\mathrm{V}$ or (inclusive disjunction)

$\varnothing$ either or (exclusive disjunction)

| not both (negated conjunction)

$\downarrow$ neither nor (negated inclusive disjunction)

$\rightarrow$ if then (sub-junction)

$\leftrightarrow$ if then and vice versa (bi - sub-junction)

The 16 truth tables are listed below and for the 7 major propositions together with verbal and symbolic expression.

\section{Proposition I}

\begin{tabular}{|c|c|c|}
\hline $\mathbf{A}$ & $\mathbf{B}$ & $\mathbf{A B}$ \\
\hline $\mathbf{1}$ & $\mathbf{1}$ & $\mathbf{1}$ \\
\hline $\mathbf{1}$ & $\mathbf{0}$ & $\mathbf{1}$ \\
\hline $\mathbf{0}$ & $\mathbf{1}$ & $\mathbf{1}$ \\
\hline
\end{tabular}

\section{Proposition II is the negation of Proposition I}

\begin{tabular}{|c|c|c|}
\hline $\mathbf{A}$ & $\mathbf{B}$ & $\mathbf{A B}$ \\
\hline $\mathbf{1}$ & $\mathbf{1}$ & $\mathbf{0}$ \\
\hline $\mathbf{1}$ & $\mathbf{0}$ & $\mathbf{0}$ \\
\hline $\mathbf{0}$ & $\mathbf{1}$ & $\mathbf{0}$ \\
\hline
\end{tabular}

\section{Proposition III}

\begin{tabular}{|c|c|c|}
\hline $\mathbf{A}$ & $\mathbf{B}$ & $\mathbf{A B}$ \\
\hline $\mathbf{1}$ & $\mathbf{1}$ & $\mathbf{1}$ \\
\hline $\mathbf{1}$ & $\mathbf{0}$ & $\mathbf{1}$ \\
\hline $\mathbf{0}$ & $\mathbf{1}$ & $\mathbf{0}$ \\
\hline $\mathbf{0}$ & $\mathbf{0}$ & $\mathbf{0}$ \\
\hline
\end{tabular}

${ }^{\star}$ Correspondence to: Gerhard Zugmaier, Department of Haematology, Oncology and Immunology, Pilipps University Marburg, Marburg, Germany, E-mail: zugmaier@staff.uni-marburg.de

Received: July 19, 2020; Accepted: July 27, 2020; Published: July 31, 2020 


\section{Proposition IV is the negation of Proposition III}

\begin{tabular}{|c|c|c|}
\hline A & B & AB \\
\hline $\mathbf{1}$ & $\mathbf{1}$ & $\mathbf{0}$ \\
\hline $\mathbf{1}$ & $\mathbf{0}$ & $\mathbf{0}$ \\
\hline $\mathbf{0}$ & $\mathbf{1}$ & $\mathbf{1}$ \\
\hline $\mathbf{0}$ & $\mathbf{1}$ & $\mathbf{1}$ \\
\hline
\end{tabular}

\section{Proposition V}

\begin{tabular}{|c|c|c|}
\hline $\mathbf{A}$ & $\mathbf{B}$ & $\mathbf{A B}$ \\
\hline $\mathbf{1}$ & $\mathbf{1}$ & $\mathbf{1}$ \\
\hline $\mathbf{1}$ & $\mathbf{0}$ & $\mathbf{0}$ \\
\hline $\mathbf{0}$ & $\mathbf{1}$ & $\mathbf{1}$ \\
\hline $\mathbf{0}$ & $\mathbf{0}$ & $\mathbf{0}$ \\
\hline
\end{tabular}

Proposition VI is the negation of Proposition V

\begin{tabular}{|c|c|c|}
\hline $\mathbf{A}$ & $\mathbf{B}$ & $\mathbf{A B}$ \\
\hline $\mathbf{1}$ & $\mathbf{1}$ & $\mathbf{0}$ \\
\hline $\mathbf{1}$ & $\mathbf{0}$ & $\mathbf{1}$ \\
\hline $\mathbf{0}$ & $\mathbf{1}$ & $\mathbf{0}$ \\
\hline $\mathbf{0}$ & $\mathbf{0}$ & $\mathbf{1}$ \\
\hline
\end{tabular}

\section{Proposition VII}

\begin{tabular}{|c|c|c|}
\hline $\mathbf{A}$ & $\mathbf{B}$ & $\mathbf{A B}$ \\
\hline $\mathbf{1}$ & $\mathbf{1}$ & $\mathbf{1}$ \\
\hline $\mathbf{1}$ & $\mathbf{0}$ & $\mathbf{0}$ \\
\hline $\mathbf{0}$ & $\mathbf{1}$ & $\mathbf{0}$ \\
\hline
\end{tabular}

\section{Verbal expression: Both $A$ and $B$}

Symbolic expression: $\mathrm{A} \wedge \mathrm{B}$

\section{Proposition VIII is the negation of Proposition VII}

\begin{tabular}{|c|c|c|}
\hline $\mathbf{A}$ & $\mathbf{B}$ & $\mathbf{A B}$ \\
\hline $\mathbf{1}$ & $\mathbf{1}$ & $\mathbf{0}$ \\
\hline $\mathbf{1}$ & $\mathbf{0}$ & $\mathbf{1}$ \\
\hline $\mathbf{0}$ & $\mathbf{1}$ & $\mathbf{1}$ \\
\hline
\end{tabular}

Verbal expression: Not both A and B

Symbolic expression: A $\mid \mathrm{B}$

\section{Proposition IX}

\begin{tabular}{|c|c|c|}
\hline $\mathbf{A}$ & $\mathbf{B}$ & $\mathbf{A B}$ \\
\hline $\mathbf{1}$ & $\mathbf{1}$ & $\mathbf{1}$ \\
\hline $\mathbf{1}$ & $\mathbf{0}$ & $\mathbf{0}$ \\
\hline $\mathbf{0}$ & $\mathbf{1}$ & $\mathbf{1}$ \\
\hline
\end{tabular}

Verbal expression: If $\mathrm{A}$ then $\mathrm{B}$

Symbolic expression: $\mathrm{A} \rightarrow \mathrm{B}$

Proposition $\mathrm{X}$ is the negation of Proposition IX

\begin{tabular}{|c|c|c|}
\hline $\mathbf{A}$ & $\mathbf{B}$ & $\mathbf{A B}$ \\
\hline $\mathbf{1}$ & $\mathbf{1}$ & $\mathbf{0}$ \\
\hline $\mathbf{1}$ & $\mathbf{0}$ & $\mathbf{1}$ \\
\hline $\mathbf{0}$ & $\mathbf{1}$ & $\mathbf{0}$ \\
\hline $\mathbf{0}$ & $\mathbf{0}$ & $\mathbf{0}$ \\
\hline
\end{tabular}

Verbal expression: $\mathrm{A}$ and not $\mathrm{B}$

Symbolic expression: $\mathrm{A} \wedge \wedge_{\mathrm{B}}$
Proposition XI the same as Proposition IX, only A and B are exchanged

\begin{tabular}{|c|c|c|}
\hline $\mathbf{A}$ & $\mathbf{B}$ & $\mathbf{A B}$ \\
\hline $\mathbf{1}$ & $\mathbf{1}$ & $\mathbf{1}$ \\
\hline $\mathbf{0}$ & $\mathbf{0}$ & $\mathbf{1}$ \\
\hline $\mathbf{0}$ & $\mathbf{1}$ & $\mathbf{0}$ \\
\hline
\end{tabular}

Verbal expression: If $\mathrm{B}$ then $\mathrm{A}$

Symbolic expression: $\mathrm{B} \rightarrow \mathrm{A}$

Proposition XII is the negation of Proposition XI

\begin{tabular}{|c|c|c|}
\hline $\mathbf{A}$ & $\mathbf{B}$ & $\mathbf{A B}$ \\
\hline $\mathbf{1}$ & $\mathbf{1}$ & $\mathbf{0}$ \\
\hline $\mathbf{1}$ & $\mathbf{0}$ & $\mathbf{0}$ \\
\hline $\mathbf{0}$ & $\mathbf{1}$ & $\mathbf{1}$ \\
\hline
\end{tabular}

Verbal expression: B and not A

Symbolic expression: $\mathrm{B} \wedge\urcorner \mathrm{A}$

\section{Proposition XIII}

\begin{tabular}{|c|c|c|}
\hline $\mathbf{A}$ & $\mathbf{B}$ & $\mathbf{A B}$ \\
\hline $\mathbf{1}$ & $\mathbf{1}$ & $\mathbf{1}$ \\
\hline $\mathbf{1}$ & $\mathbf{0}$ & $\mathbf{1}$ \\
\hline $\mathbf{0}$ & $\mathbf{1}$ & $\mathbf{1}$ \\
\hline
\end{tabular}

Verbal expression: A or B or both

Symbolic expression: A v B

Proposition XIV is the negation of Proposition XIII

\begin{tabular}{|c|c|c|}
\hline $\mathbf{A}$ & $\mathbf{B}$ & $\mathbf{A B}$ \\
\hline $\mathbf{1}$ & $\mathbf{1}$ & $\mathbf{0}$ \\
\hline $\mathbf{1}$ & $\mathbf{0}$ & $\mathbf{0}$ \\
\hline $\mathbf{0}$ & $\mathbf{1}$ & $\mathbf{0}$ \\
\hline
\end{tabular}

Verbal expression: Neither A nor B

Symbolic expression: A $\downarrow$ B

Proposition XV

\begin{tabular}{|c|c|c|}
\hline $\mathbf{A}$ & $\mathbf{B}$ & $\mathbf{A B}$ \\
\hline $\mathbf{1}$ & $\mathbf{1}$ & $\mathbf{1}$ \\
\hline $\mathbf{1}$ & $\mathbf{0}$ & $\mathbf{0}$ \\
\hline $\mathbf{0}$ & $\mathbf{1}$ & $\mathbf{0}$ \\
\hline
\end{tabular}

Verbal expression: If $A$ then $B$ and vice versa

Symbolic expression: $\mathrm{A} \leftrightarrow \mathrm{B}$

Proposition XVI is the negation of Proposition XV

\begin{tabular}{|c|c|c|}
\hline $\mathbf{A}$ & $\mathbf{B}$ & $\mathbf{A B}$ \\
\hline $\mathbf{1}$ & $\mathbf{1}$ & $\mathbf{0}$ \\
\hline $\mathbf{0}$ & $\mathbf{0}$ & $\mathbf{1}$ \\
\hline $\mathbf{0}$ & $\mathbf{1}$ & $\mathbf{1}$ \\
\hline
\end{tabular}

Verbal expression: Either A or B but not both

A Symbolic expression: A ø B 
The number of the 7 logical operators outlined above can be further reduced but at the price of simplicity. In fact, all connectives can be expressed by using the operator | (Not both). Also, by using the operator $\downarrow$ (Neither nor) all connectives can be expressed. That was already demonstrated more than 100 years ago by Peirce, Sheffer and Nicod [13].

The more operators used the shorter are the formula, the less operators used, the longer the formula are.

For example, if the $\mathrm{A} \leftrightarrow \mathrm{B}$ is avoided, it needs to be replaced by (A $\rightarrow \mathrm{B}) \wedge(\mathrm{B} \rightarrow \mathrm{A})$, another option would be to express $\mathrm{A} \leftrightarrow \mathrm{B}$ as $\neg \mathrm{A} \wedge \neg$ $\mathbf{B} \mathbf{v} \mathbf{A} \wedge \mathbf{B}$.

\section{Logic in medicine}

The role of sentential logic in medical diagnosis was described in various publications in 20th century [2,4]. There has been agreement that there is no diagnosis without logic $[4,6]$. It was even claimed that the best textbook of Medicine is Jevon's "Foundation of Logic" [6].

The disadvantage of symbolic sentential logic is the lack of differentiation between findings, causes of disease and disease. It is furthermore not possible to put all permutations of findings into a complete logical framework [4]. It will always be the investigator's task to reconcile the logical models with clinical reality. The purpose of the formalized diagnostic method is not to replace the physician, but rather to give her or him an additional tool for the diagnostic process at hand, to minimize the risk of having overlooked something.

\section{Acute lymphoblastic leukemia (ALL)}

ALL (also called acute lymphocytic leukemia) is an aggressive type of leukemia characterized by the presence of too many, clonal lymphoblasts or lymphocytes in the bone marrow and peripheral blood. It can spread to the lymph-nodes, spleen, liver, central nervous system (CNS), and other organs. Without treatment, ALL usually progresses quickly and causes the patient's death. ALL occurs in both children and adults. It is the most common type of cancer of childhood. The chance of cure of patients with ALL has dramatically increased over the last 3 decades, mainly because of better diagnostic tools and better characterization of risk factors predicting outcome [13]. Diagnostic techniques include cytomorphological evaluation, immunophenotyping and identification of recurrent genetic alterations, most of which absolutely peculiar of BCP-ALL [e.g., $t(12 ; 21), t(17 ; 19)$, $t(1 ; 19)]$. Essential for this standardized process are central laboratories for all diagnostic tests [14]. The advanced knowledge of the classification of BCP-ALL has been implemented into the most recent edition of the World Health Organization (WHO) Classification of Tumors of Haematopoietic and Lymphoid tissues [15]. Immunophenotyping by flow-cytometry (FCM) is an essential component of the diagnostics and the definition of leukemia.

Immune phenotyping by determination of clustered designation (CD) antigen, expressed on the cell surface of leukemia elements, is a widely used method to classify leukemia. This is demonstrated at the example of BCP-ALL. The acronym CD is used for expression of the Antigen. The rate of expression is defined by the WHO [15] criteria: negative, positive weak, positive strong. The immune phenotypic definition of BCP ALL is complex. It is based on the 4 antigens CD19b; CD10, CD22, CD79a. BCP-ALL needs strong positivity in at least 2 of the four antigens; in the very rare case of CD19-negativity, specifically CD10 must be "strong positive". Leukemic blasts differ from normal blast with either over- or under-expression of many markers including CD10, CD 38, CD45, CD58 and/or expression of TdT.
Although the immune phenotypic definition of BCP ALL is correctly expressed in verbal terms, mathematical logic may present the definition in a clearer way as shown below.

BCP ALL $\leftrightarrow($ CD19 strong v CD10 strong $) \wedge($ CD22 strong $\mathrm{v}$ CD79a strong $) \wedge($ CD45 strong v CD45 weak v CD38 strong v CD38 weak v CD58 strong v CD58 weak v TdT)

By the symbols of mathematical logic, the definition of BCP-ALL is shown concisely, while the content is the same as the one outlined in the text. Mathematical logic provides the tools to ensure that the necessary and sufficient conditions for diagnosis are available to the treating physician. It strips natural language from all ambiguous elements [16]. In case of BCP-ALL it is not only essential to discriminate this disease form other leukemias, but also to discriminate the leukemic cells from normal cells. By conventional morphological methods, the latter is extremely challenging or even impossible. This often resulted in diagnosis of BCP ALL at a very late stage of disease with complications of treatment. The discrimination of leukemic cells from normal cells enables the detection of BCP-ALL at an early stage of disease and at a low level of disease burden [14]. The concept of treatment at minimal residual disease (MRD) level has resulted in better outcome and less side effects of treatment [17].

\section{References}

1. Sackett DL (1996) Evidence based medicine: what it is and what it isn't. BMJ 312 71-72. [Crossref]

2. Bieganski W (1909) Medizinische Logik, Kritik der ärztlichen Erkenntnis, Fabian

3. Bochenski JM (1962) Formale Logik, Karl Alber, Freiburg

4. Gross G, Löffler M (1997) Prinzipien der Medizin, Springer, Heidelberg

5. Mainzer F (1925) Über die logischen Prinzipien der ärztlichen Diagnose in Schaxel J., Abhandlungen zur Theoretischen Biologie, Gebrüder Bornträger, Berlin

6. Cohen H (1943) The nature of methods and purpose of diagnosis. Lancet 24: 1-10.

7. Thiel C (1967) Sinn und Bedeutung in der Logik Gottlob Freges, Philosophische Forschung, Monographie 43, A. Hain, Meisenheim.

8. Peano (1889) The prinicples of arithmetic presented by a new method in Heijencourt J., From Frege to Gödel, Harvard University Press, Cambridge, London

9. Slater JG (1997) The Collected Papers of Bertrand Russell, Volume 11, Routledge, Oxon.

10. Wittgenstein L (1992) Tractatus logico-philosophicus, Suhrkamp, Berlin

11. Post E (1921) Introduction to a general theory of elementary proposition in Heijencourt J., From Frege to Gödel, Harvard University Press, Cambridge, London

12. Lukasiewicz J, (1957) Aristoteles' Syllogistik, Blackwell, Oxford

13. Hilbert D. and Bernays Paul, (1968) Grundlagen der Mathematik I Springer, Berlin, Heidelberg, New York

14. Moericke A (2008) Risk adjusted therapy of acute lymphoblastic leukemia can decrease treatment burden and improve survival: treatment results of 2169 unselected pediatric and adolescent patients enrolled in the trial ALL-BFM 95. Blood 111: 4477-4489 [Crossref]

15. Zugmaier G (2019) Aneuploidy in childhood B cell acute lymphoblastic leukaemia - also a relevant prognostic factor in relapsed disease. Br J Haematol 184: 895-896. [Crossref]

16. Swedlow SH (2017) WHO Classification of Haematopoietic and Lymphatic Tumours, $4^{\text {th }}$ Edition, IARC, Lyon 2017

17. Halbach V (2010) The Logic Manual, Oxford University Press, Oxford 2010

18. Locatelli F (2012) How I treat relapsed childhood acute lymphoblastic leukemia. Blood 120: 2807-2816. [Crossref]

Copyright: (C2019 Zugmaier G. This is an open-access article distributed under the terms of the Creative Commons Attribution License, which permits unrestricted use, distribution, and reproduction in any medium, provided the original author and source are credited. 